\title{
Docência: Psicodinâmica e relações de trabalho
}

\author{
Teaching: Psychodynamics and labor relations
}

\author{
Juliana Zanini Pereira ${ }^{[a]}$, Elisete Soares Traese ${ }^{[b]}$, Álvaro Roberto Crespo Merlo ${ }^{[c]}$
}

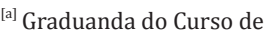
Psicologia do Centro Universitário Franciscano (Unifra), Santa Maria, RS - Brasil, e-mail: jully_zanini@hotmail.com

${ }^{\left[{ }^{[b]}\right.}$ Docente do Centro Universitário Santa Maria, Rio Grande do Sul, mestre e doutoranda em Psicologia Social e Institucional pela Universidade Federal do Rio Grande do Sul (UFRGS), membro do Laboratório de Psicodinâmica do Trabalho/ UFRGS, Porto Alegre, RS - Brasil, e-mail: elisetetraesel@unifra.br

${ }^{[c]}$ Docente do Programa de Pós-Graduação em Psicologia Social (PPGPSIC) da Universidade Federal do Rio Grande do Sul (UFRGS), membro do Laboratório de Psicodinâmica do Trabalho/ UFRGS, Porto Alegre, RS - Brasil, e-mail: merlo@ufrgs.br
}

Recebido: 13/06/2011 Received: 06/13/2011

Aprovado: 14/09/2011 Approved: 09/14/2011

\section{Resumo}

Este trabalho consiste em uma pesquisa qualitativa realizada com professores do Ensino Médio de uma escola pública de uma cidade do interior do estado do Rio Grande do Sul. Tal investigação teve o objetivo de analisar como se encontram estruturadas as relações no trabalho docente na contemporaneidade e quais seus impactos sobre a saúde e a subjetividade desse trabalhador. A metodologia utilizada foi a psicodinâmica do trabalho. Pôde-se constatar que o educador encontra-se inserido em um contexto de intensos desafios, múltiplas exigências e pressão por resultados. Constatou-se, ainda, que o prazer obtido através do reconhecimento está associado à intensa dedicação e sobrecarga. Por fim, percebeu-se que as relações são baseadas nas exigências pedagógicas, sendo que há pouco espaço para o não trabalho, para a interlocução e para outros relacionamentos, o que indica que necessitam de um espaço de convivência e de fortalecimento dos laços de cooperação em busca de relações de trabalho mais saudáveis.

Palavras-chave: Trabalho docente. Saúde e subjetividade. Psicodinâmica do trabalho.

\section{Abstract}

This work is a qualitative survey conducted among high school teachers in a public school in a town in the state of Rio Grande do Sul, Brazil. This study aimed to analyse how are structured the relations at teaching work in contemporary and what their impacts on the health and subjectivity of this worker. The methods used were the psychodynamics of work. It was found that the educator is inserted in a context of intense challenges, multiple demands and pressure for results. We confirmed that the pleasure obtained through recognition is associated with intense dedication and overload. Finally, it was noted that the relations are based on educational requirements, and there is little to no work, for dialogue and for other relationships, which indicates that require a space of coexistence and of strengthening ties of cooperation in search of employment relationships healthier.

Keywords: Teaching work. Health and subjectivity. Pychodynamics of work. 


\section{Introdução}

Observa-se, nos dias de hoje, que as relações interpessoais estão passando por um processo de fragilização: os relacionamentos são passageiros e superficiais, dando-nos a impressão de que laços sólidos não são mais priorizados pelos indivíduos. Tal fragilidade não se reduz aos relacionamentos amorosos; pode também se observar a falta de envolvimento nas relações familiares, nas amizades, nas relações de vizinhança e nas relações no ambiente de trabalho.

A sociedade se caracteriza pelo imediatismo; na pressa por obter resultados, está deixando de lado os laços afetivos e a convivência com os demais. Nesse sentido, nota-se que as pessoas estão passando muito tempo do seu dia no ambiente de trabalho, quando não acabam levando trabalho para seus domicílios, reduzindo cada vez mais, o tempo de não trabalho e o investimento em laços afetivos.

Apesar disso, aprofundando esse assunto, deve-se considerar a importância do trabalho na constituição dos sujeitos. Sendo assim, a forma como os indivíduos se relacionam com seu trabalho e todas as consequências que o exercício de sua profissão acarreta têm influência direta na subjetividade e na maneira como esse sujeito irá se relacionar nas demais áreas de sua vida.

Dejours (2004) considera que o ato de trabalhar é algo que coloca a subjetividade à prova, podendo agregar valor a ela ou empobrecê-la e diminuí-la. Sendo assim, o trabalho, cada vez mais competitivo, e as exigências cada vez maiores de nossa sociedade consumista e ávida por resultados têm gerado consequências como desinteresse, sofrimento e desgaste emocional e físico.

De acordo com Mazzotti (2007), diante da pouca importância dada à profissão e da falta de recursos para a realização de suas tarefas, os professores estão abalados, o que nos remete à importância de um olhar diferenciado para suas dificuldades e seus sofrimentos.

Sendo assim, o trabalho buscou investigar como os professores estão vivenciando suas relações de trabalho, quais as dificuldades e os desafios enfrentados por esses em sua profissão e quais as estratégias que eles utilizam para vencer esses desafios.
Esta pesquisa também visou a analisar as dinâmicas de sofrimento e prazer dentro do contexto docente, investigando, assim, se esses profissionais, apesar das dificuldades vinculadas ao trabalho, conseguem ressignificar e transformar suas vivências em prazer e realização (Dejours, 1999, 2001, 2008).

\section{Relações contemporâneas}

As relações contemporâneas encontram-se, inevitavelmente, vinculadas ao consumismo. De acordo com Bauman (2001), a vida está organizada ao redor do consumo, sendo orientada pela sedução por desejos crescentes e vontades voláteis ao invés de regulações normativas.

Nota-se, também, que as relações na contemporaneidade estão assentadas na instantaneidade. Segundo o autor, essa pressa, além de significar realização imediata, também representa o empobrecimento e desaparecimento do interesse, gerando uma mudança significativa na convivência das pessoas, principalmente, no que diz respeito aos cuidados com suas tarefas coletivas.

Essa sociedade imediatista possui uma urgência em obter resultados, sendo que os indivíduos não querem se prender aos relacionamentos, uma vez que estabelecer vínculos exige maior dedicação e desgaste emocional. No entanto, os relacionamentos passageiros contemporâneos servem como disfarces para uma busca incansável pelo pertencimento (Bauman, 2004, 2001).

No que diz respeito aos laços institucionais, estes também, como os sociais, estão enfraquecidos. Nessa direção, Sennett (2003) considera que as redes institucionais modernas caracterizam-se por laços fracos demonstrando, com isso, que as associações breves são mais úteis aos indivíduos do que as de longo prazo e que laços sociais como a lealdade, por exemplo, deixaram de ser interessantes.

Codo e Jacques (2002) consideram que o mundo do trabalho tornou-se, nas últimas décadas, um ambiente de insegurança, incerteza e negociação constante das condições de permanência no emprego, além de vir consumindo o espaço íntimo dos trabalhadores e interferindo, cada vez mais, 
na relação com o cônjuge e com os filhos, o que gera profundos impactos no mundo do trabalho.

Impactos das formas atuais de relacionamentos sobre o mundo do trabalho

Conforme Dejours (2004), o trabalho passa, primeiramente, pela experiência afetiva do sofrimento. Trabalhar não é apenas produzir, é também transformar a si mesmo. $\mathrm{O}$ ato de trabalhar, além de apresentar uma significação narcísica, pode também carregar investimentos da ordem simbólica destinados a um objeto (Dejours, 1992).

Para Freud citado por Mendes (2010), o trabalho pode ser fundamental na vida do indivíduo, pois se transforma em uma das dimensões da existência do homem, sendo que é através deste que a sublimação, o mecanismo de defesa mais evoluído, opera, possibilitando assim que o sujeito vivencie o prazer no trabalho através da transformação da pulsão em gratificação social.

Navarro e Padilha (2007) consideram que o trabalho ocupa parte considerável do tempo e espaço em que a vida humana contemporânea se desenvolve. Ele não é apenas um meio de satisfação das necessidades básicas, mas sim uma fonte de identificação, de autoestima e de potencialidades. Essa centralidade do trabalho na vida dos indivíduos não se dá apenas na esfera econômica, mas também na psíquica.

Nesse sentido, Codo (1999) analisa que aquele trabalhador que não consegue dividir suas dificuldades e preocupações mais íntimas apresenta aumento em sua tensão emocional no ambiente de trabalho; e, se esse profissional necessitar de um apoio afetivo e não o obtiver, sua tendência será fechar-se em si mesmo, o que aumentará seu sofrimento.

Sendo assim, Dejours (1999) considera que o trabalho possui efeitos muito intensos sobre o sofrimento psíquico. Este pode tanto agravar o sofrimento do indivíduo, levando-o, por vezes, à loucura, como contribuir para a transformação em prazer. O sofrimento pode ser compensado por estratégias coletivas de defesa, que mantêm o sujeito em um estado de normalidade, mas também obstam a emancipação e a mudança.

Conforme Lancman citado por Dejours (2008), as estratégias de defesa coletiva são utilizadas pelos sujeitos como uma forma de proteção do seu aparelho psíquico contra o funcionamento de algumas organizações de trabalho. No entanto, essas defesas também apresentam um lado negativo, pois têm a função de adaptação, essa aqui entendida como algo que pode impedir a tomada de consciência desses sujeitos ante as relações de poder.

Dejours $(1999,2008)$ ainda introduz o conceito de espaço de discussão como sendo de grande importância para o aprimoramento das organizações de trabalho. Este consiste em um espaço destinado aos indivíduos para que possam debater suas opiniões de forma democrática, propiciando um lugar de escuta a esses trabalhadores. Esse espaço de discussão e convivência faz-se fundamental no contexto do trabalho docente, conforme estudos apresentados na próxima seção.

\section{0 contexto do trabalho docente}

A docência se fundamenta na interação humana, porque se realiza no encontro entre dois ou mais sujeitos, sendo complexa e paradoxal. Isso porque o professor, inevitavelmente, terá de conviver com diversas contradições, uma vez que depende da disponibilidade do outro para que possa executar sua intenção de construção e de mudança.

Pode ser considerada ainda uma tarefa impossível, pois as condições de seu exercício, juntamente com as resistências dos alunos, impedem que o professor, seguidamente, atinja seus objetivos. Assim, para exercer essa profissão com tranquilidade, é preciso saber o que depende da sua ação como profissional e o que não é de sua competência, além da compreensão de que não pode carregar e nem assumir todas as culpas (Perrenoud, 2001, 2002).

Para Perrenoud (2002), a formação do futuro professor deve prepará-lo para pensar sobre sua prática, criar novas formas de trabalhar, além de exercer sua capacidade de observação e análise; ressalta-se, porém, que isso só é alcançado quando se compartilham vitórias e fracassos.

Considerando esse cenário, Esteve (1999) aponta que, atualmente, os professores se deparam com uma nova fonte de mal-estar no que diz respeito à definição do que devem fazer, quais valores devem defender. Nessa perspectiva, o autor explica que os sintomas mais comuns apresentados pelos professores são a falta de compromisso, baixa autoestima e incapacidade de levar o trabalho a sério. Os professores encontram-se insatisfeitos e desmotivados 
para realizarem suas atividades, o que irá implicar em uma diminuição do seu esforço e interesse, resultando na realização do trabalho somente como forma de subsistência e não como uma fonte de prazer e realização.

No entanto, nem todos os professores reagem a isso da mesma forma. Esteve (1999) ainda afirma que uma grande parte deles consegue romper com esse mal-estar a partir de propostas criativas e inovadoras para enfrentar os problemas. No entanto, deve-se salientar que os números mais significativos são daqueles que fazem da inibição e da acomodação uma forma de defesa diante das situações conflitivas, mantendo-se em seu trabalho, mas sem enfrentar e resolver seus desafios.

\section{Método}

A presente pesquisa foi realizada com o método da Psicodinâmica do Trabalho (Dejours, 2008). Este se baseou na observação clínica, quando o pesquisador analisa os fatos decorridos durante a pesquisa e procura interpretá-los, buscando, assim, fatores que reflitam o conteúdo das vivências de prazer e sofrimento, as contradições e conflitos relativos ao trabalho (Dejours, 1992).

Conforme Merlo e Mendes (2009), o objeto desse método de pesquisa é o estudo das relações entre a organização do trabalho e os processos de subjetivação. 0 acesso a essas relações se dá através da palavra, que permite que o sofrimento seja reelaborado, reconhecido e discutido coletivamente, fortalecendo as relações de empatia e solidariedade dentro da organização. Falar e refletir sobre seu trabalho é uma maneira de levar os trabalhadores a agir sobre sua prática.

Participaram da pesquisa três professores: Mariana, 46 anos, educadora especial; Vanessa, 61 anos, professora de matemática; e Rodrigo, 44 anos, professor de matemática. Salienta-se que esses são nomes fictícios. Os participantes são professores em uma escola pública de Ensino Fundamental e Médio de um município do interior do estado do Rio Grande do Sul, escolhidos por conveniência tendo em vista a adesão ao convite aberto aos professores de Ensino Médio da escola.

No que diz respeito aos dados da pesquisa, esses foram obtidos através de grupos de discussão baseados na metodologia da Psicodinâmica do Trabalho (Dejours, 2008). Foram realizados com o grupo dois encontros com a duração de, aproximadamente, duas horas. 0 número de encontros foi reduzido porque os participantes tinham pouca disponibilidade de horários.

A psicodinâmica do trabalho como método de pesquisa consiste na escuta coletiva de grupos realizados em um local que possua uma identificação com o trabalho (Dejours, 2008). Tal método prioriza o coletivo e não os indivíduos, visando sempre intervenções direcionadas para a organização do trabalho em que os sujeitos encontram-se inseridos (Merlo \& Mendes, 2009).

Já no que se refere aos procedimentos éticos, os participantes, após receberem todas as informações sobre a finalidade da pesquisa, receberam e assinaram o Termo de Compromisso Livre e Esclarecido, previamente explicado pelos pesquisadores. A pesquisa foi também autorizada pela instituição onde foi realizada.

Foi esclarecido a cada participante que o material das entrevistas seria utilizado somente para fins de pesquisa, que sua identidade seria mantida em sigilo e as gravações seriam destruídas logo após a transcrição das entrevistas. Salienta-se, ainda, que a pesquisa somente teve início após aprovação pelo Comitê de Ética do Centro Universitário Franciscano (Unifra).

Esta pesquisa seguiu os princípios éticos da pesquisa com seres humanos de acordo com a Resolução n. 196/96 do Conselho Nacional de Saúde, que incorpora sob a ótica do indivíduo e das coletividades os quatro princípios básicos da bioética: autonomia, não maleficência, beneficência e justiça; essa resolução também visa assegurar os direitos e deveres que dizem respeito à comunidade científica, aos sujeitos da pesquisa e ao Estado.

A análise dos dados foi realizada a partir do procedimento de análise de conteúdo, que consiste em um conjunto de técnicas de análise das comunicações objetivando obter, por procedimentos sistemáticos e objetivos de descrição do conteúdo das mensagens, indicadores qualitativos ou não que possibilitam a inferência de conhecimentos relativos às condições de produção destas mensagens (Bardin, 2004). As categorias foram definidas em etapa prévia à coleta de dados, tendo em vista os objetivos da pesquisa. 


\section{Resultados e discussão}

0 que é ser professor?

Esta categoria pretende discorrer sobre qual o significado e as representações do ser professor para os participantes, visando compreender o que caracteriza essa profissão e quais os desafios e as dificuldades enfrentadas por estes.

Através da fala dos professores, pode-se constatar a existência de diferentes visões sobre o que é ser professor. Vários fatores foram identificados nas respostas, sendo evidenciados tanto aspectos técnicos quanto aspectos mais subjetivos, apontando, assim, as demandas atuais sobre a profissão, como se observa na fala de Vanessa: "A gente está assumindo como professor além do ensino da nossa disciplina, a educação, a postura... Acaba até falando sobre sexo, namoro, uma série de coisas, porque a família não faz mais isso". Outra participante (Mariana) também refere em sua fala essas novas atribuições destinadas aos professores:

Ser professor mudou bastante, antes tu só precisava transmitir conhecimento, ensinar o que tua disciplina exige, mas agora exigem muito mais do que isso dos professores. Tu tens que dar tua disciplina, tu tens que educar aluno, ensinar a eles como devem se comportar, impor limites, coisas que antes não eram teu papel.

Conforme Esteve (1999), as responsabilidades e as exigências destinadas aos professores vêm aumentando concomitantemente às mudanças do contexto social. Tal cenário ocasionou transformações no papel dos professores o que, em determinados casos, tornou-se um fator desencadeante de mal-estar, já que não estão sabendo como conviver e aceitar essa nova realidade.

Nesse sentido, Aguiar (2008) considera que o mal-estar docente está relacionado às dificuldades que a escola e os docentes estão enfrentando para acompanhar as mudanças sociais que vem ocorrendo. Assim, esses agentes estão sujeitados a questões de cunho familiar e social decorrentes da crise de valores da sociedade atual.

Pode-se constatar, também, que a docência é considerada pelos professores como parte constituinte da sua personalidade, sendo definido como algo que os caracteriza, os identifica. É possível observar isso na fala de Vanessa: “... eu digo que a gente não fica professor, a gente nasce professor, então a gente tem um pouco no sangue isso". A fala de Rodrigo também aborda essa questão: "Eu estou sempre comprando livros de matemática, sento com livros de estatística e minha esposa com outros livros. Ela está sempre brigando comigo por que só compro livros didáticos".

Conforme Freud, o ato de trabalhar pode ser uma maneira de atingir a felicidade, assumindo um papel fundamental na vida dos indivíduos, sendo possível considerá-lo uma dimensão da sua própria personalidade (Mendes, 2010).

Nesse sentido, Codo (1999) aponta que o trabalho, entendido aqui como uma atividade de transformação e criação, também modifica o sujeito que o pratica. Este se reconhece no seu trabalho e se orgulha dos resultados obtidos, passando, assim, por transformações ao longo desse processo, como alterações em seu modo de vestir, se comportar, em seus gostos e hábitos.

Um aspecto importante apresentado pelos participantes refere-se à percepção da necessidade de estarem sempre reinventando sua maneira de dar aula, com a finalidade de manter a atenção de seus alunos. Tal flexibilidade pode ser evidenciada na fala de Rodrigo: "Eu gosto da metodologia tradicional, mas isso não quer dizer que eu não posso usar de outros recursos para acessar o aluno". E ainda na fala de Vanessa:

Eu continuei estudando, fazendo cursos, inventei moda, pastas chamadas portfólios, mapas conceituais que encontrei na internet, tudo isso eu trabalho com meu aluno.... Então eu cheguei à conclusão de que tu tens que variar para pegar um, pegar outro.

Perrenoud (2001) considera que a escola e o ato de educar estão em um constante processo de renovação, sem com isso perder sua essência. A escola deve se manter aberta aos novos saberes, às novas metodologias e tecnologias sem que, para isso, necessite abandonar seus antigos conhecimentos e técnicas. 0 professor precisa estar preparado para refletir a respeito de suas práticas, criando, caso necessário, novas técnicas e formas de ensinar. Também precisa se manter em constante observação e reflexão de seus acertos e equívocos juntamente com os colegas, visando um constante aprendizado (Perrenoud, 2002). 
Nesse sentido, percebe-se que a capacidade de criação é fundamental, pois possibilita a esse trabalhador ir para além do trabalho prescrito, dando sua contribuição à organização de trabalho (Dejours, 1999, 2008). Entretanto, a tentativa de mudar continuamente para atender seu cliente, nesse caso o aluno pode levar os professores a um intenso sofrimento por sentirem esgotar sua capacidade de inovação diante das múltiplas exigências demandadas por seus alunos na atualidade.

Os professores do grupo referem que essa necessidade de estar sempre buscando algo novo foi identificada como uma fonte de sobrecarga, pois, diante dos inúmeros estímulos que a sociedade oferece aos seus alunos, nem sempre conseguem alcançar seus objetivos apesar de seus esforços, o que os leva a se sentirem fracassados e menosprezados, como ilustra a fala de Vanessa: “... eu vejo uma sobrecarga em cima dos professores, estar sempre pensando em novas didáticas para conseguir prender atenção dos alunos, fazer com que eles se interessem pelo conteúdo e isso exige muito do professor".

Conforme Aguiar (2008), encontram-se hoje adicionadas ao papel do professor demandas que não competiam a eles. 0 professor se vê obrigado a se envolver com questões referentes às crises de valores de nossa sociedade, problemas de ordem familiar, dentre outros, havendo assim uma discrepância entre o ideal do ensino e a realidade.

Nesse sentido, para Esteve (1999), o docente está sobrecarregado, e vê-se obrigado a realizar uma prática fragmentada na qual deve vivenciar situações contraditórias. Estes estão vivenciando as consequências da exposição a um número cada vez maior de tensões no exercício de sua profissão, por causa das novas dificuldades e responsabilidades que lhes vem sendo exigidas sem que lhes sejam fornecidas condições adequadas para enfrentar tais circunstâncias.

Aprofundando a questão, ficou evidente que o crescente desinteresse dos alunos gerou um desânimo nos professores, desestimulando os profissionais; isso se confirma na fala de Vanessa: "Aluno é todo aquele jovem matriculado em uma escola, estudante é aquele que estuda.... Esses que são somente alunos, são os que nos frustram, antigamente eram poucos hoje é maioria". Rodrigo endossou essa opinião:

A gente fica frustrado com alunos assim, nada prende a atenção deles por muito tempo, tu está ali na frente e eles simplesmente não estão interessados. Se eu tivesse um grupinho de alunos assim dedicados, interessados eu teria mais gosto em vir para a sala de aula.

Souza citado por Aguiar (2008) considera que os professores sofrem uma degradação profissional e pessoal ao se depararem com o desinteresse dos alunos, pois esse de certa forma o desloca de seu lugar de mestre. Alunos que não querem aprender fazem com que os professores tomem para si o fracasso daqueles. Nesse sentido, Oliveira (2004) aponta que, diante das mais variadas funções assumidas hoje pela escola pública, o professor se vê obrigado a realizar tarefas que estão além da sua formação. Tais profissionais precisam, muitas vezes, suprir demandas que seriam de assistentes sociais, psicólogos, enfermeiros, dentre outros.

Desse modo, outro aspecto bastante relevante que remete ao sofrimento docente refere-se ao fato de os professores terem de assumir funções que até então eram responsabilidade dos pais. Os docentes se sentem abandonados pelos pais, situação confirmada na fala de Rodrigo: “... os pais nos deixaram sozinhos, os pais não participam mais, não se interessam pela escola, apenas nos entregaram os filhos deles para que nós sejamos responsáveis". Ainda nesse sentido, Mariana comenta:

Os pais nos deixaram sozinhos e ainda nos colocaram uma responsabilidade que é deles.... Os pais não sabem o que os filhos fazem, e querem jogar para nós essa responsabilidade de educar os alunos, ensinar coisas que eles já deveriam vir de casa sabendo.

Uma das queixas dos professores, nos dias de hoje, é de que os pais não se preocupam em transmitir para seus filhos valores básicos, julgando ser isso uma tarefa exclusiva do professor; além disso, se mostram dispostos a culpar somente o professor pela má-educação de seus filhos (Esteve, 1999). Segundo Aguiar (2008), todas essas exigências que os pais vêm delegando aos professores surtem um "efeito devastador" sobre os professores; uma vez que não conseguem responder a essas exigências, padecem, certas vezes, no adoecimento e em um sentimento profundo de incompetência.

De tal modo, observou-se que todas essas dificuldades têm influenciado diretamente a saúde dos professores. Os participantes relataram problemas 
relacionados à saúde física e mental, como demonstrado nesse relato de Rodrigo: "Eu estou tendo esse problema a cada duas ou três vezes no ano eu perco a voz e não consigo dar aula". O depoimento de Vanessa também aborda esse aspecto:

Outro problema que nós temos são os problemas físicos. Agora eu diminuo, mas quando eu dava muita aula, em outubro, minha voz começava a falhar.... Tem professores doentes, tem professores que entram em laudo por problemas de depressão, outros por doenças mil.

Nesse contexto, Aguiar (2008) aponta que o professor está passando por um adoecimento existencial, pois não tem suportado as angústias e dificuldades que agora fazem parte do cotidiano da profissão. A rotina escolar o sobrecarrega; por causa do intenso envolvimento afetivo, ele sofre um desgaste emocional que resultará no desenvolvimento de sintomas físicos e psíquicos.

Com relação a esse assunto, Martins (2010) aponta a existência de um crescimento no número de doenças vinculadas ao trabalho na contemporaneidade. No que se refere à profissão docente, são as vivências de sala de aula os principais motivos que acarretam o adoecimento desses profissionais (Aguiar, 2008).

No entanto, apesar de todas essas dificuldades, observou-se que os professores sentem que seu trabalho, seu esforço e seu sofrimento são reconhecidos nessa escola e por alguns alunos, sendo isso o que lhes dá satisfação com a profissão, como se percebe nas seguintes falas: "O que me dá satisfação é ver que somos valorizados, que esse colégio realmente reconhece nosso trabalho" (Rodrigo); "Porque a satisfação que eu tenho na aula é quando o aluno mostra que entendeu, ou pergunta se não entendeu, estão atentos às explicações, porque este aluno te dá satisfação, ele está valorizando o teu trabalho" (Vanessa); "... tu podes ensinar aos outros, acho isso fascinante" (Mariana).

Dejours $(1999,2008)$ aponta o reconhecimento como sendo o que dá sentido ao sofrimento no trabalho, pois quando o sujeito tem seu trabalho reconhecido isso significa que esse sofrimento não foi em vão, que todas as suas angústias, frustrações e dúvidas tiveram um motivo. Em concordância, Lancman citado por Dejours (2008) considera que a transformação do sofrimento em prazer e a constituição da identidade estão relacionadas ao reconhecimento do outro, sendo que, na ausência desse reconhecimento, o trabalho deixa de existir, espalhando essa desvalorização para outras esferas da vida do trabalhador.

Quanto ao reconhecimento de seu trabalho pelos colegas, alunos e equipe diretiva, os participantes da pesquisa referiram que se sentem reconhecidos pelo seu trabalho. Isso, certamente, contribui para a preservação da saúde desses profissionais, nesse contexto, embora haja dúvidas quanto à sua eficácia, tendo em vista as condições em que ocorre esse reconhecimento, conforme será retomado adiante.

Esse reconhecimento fica evidente no trecho da fala de Rodrigo: "... nós temos um envolvimento com a escola, nós temos uma identificação com a escola, e dá para notar que nós somos reconhecidos de certa maneira e isso é muito bom. Entra e sai direção, o reconhecimento é o mesmo". Vanessa também salienta esse reconhecimento:

... a gente tem a satisfação quando o aluno responde à nossa solicitação, responde, essa tua expectativa de estar estudando, o que cada vez são menos. Outra coisa que me dá satisfação é realmente o reconhecimento dos colegas, dos setores... eu sinto nas pessoas um respeito pelo meu trabalho (Vanessa).

De acordo com Ferreira (2010), o reconhecimento no trabalho está relacionado aos significados que o trabalhador atribui ao contexto onde trabalha; está, geralmente, interligado aos sentimentos de valorização, admiração, envolvimento e pertencimento, o que influencia, consideravelmente, a visão que o sujeito apresenta sobre o próprio trabalho, o nível de investimento, motivação e satisfação. Nesse sentido, Gernet (2010) aponta que é através do reconhecimento que o sofrimento ocasionado pelo trabalho ganha significado; o reconhecimento conferido ao trabalho do indivíduo é um elemento imprescindível para que o trabalho se confirme como construtor da identidade.

No entanto, nota-se que tal reconhecimento aparece aqui como uma possível estratégia de defesa dos professores diante do desgaste e do sofrimento vinculado à profissão. Percebeu-se que os professores buscaram frisar que, apesar das dificuldades, sentem-se reconhecidos pela escola. Sendo assim, infere-se que o reconhecimento está ligado à sua capacidade de se submeter às exigências em demasia, 
à sobrecarga e aos poucos recursos, o que acaba por proliferar essas más condições de trabalho, culminando com o adoecimento. Tal constatação pode ser observada no trecho a seguir:

Às vezes tu está no quadro tentando explicar uma coisa que eu sei que a turma não quer, eu penso o que eu estou fazendo aqui? Mas a gente consegue ainda entrar em uma sala de aula e esquecer tudo de problema e começar de novo (Vanessa).

Outra estratégia de defesa constatada foi o isolamento dos professores em um grupo de iguais. Por exemplo, em suas falas, reforçaram que há união e cooperação entre os professores de matemática das séries iniciais, passando a sensação de que estes se apoiam mutuamente, o que parece os proteger das dificuldades e impasses provenientes da organização do trabalho. Isso fica evidenciado nas palavras de Rodrigo: "Nós montamos certo clube junto com os nossos colegas das séries iniciais, porque pensamos na escola, trabalhamos por esse colégio e por nossos alunos".

Outra estratégia defensiva relaciona-se ao trabalho em excesso, deixando de usufruir o tempo de descanso, para resolver problemas junto aos colegas, tentando abrir um espaço de discussão, conforme refere Vanessa: "Tu sabe que nós aqui fizemos uma coisa errada. Os outros professores usam o recreio para descansar, mas nós três ficamos conversando sobre as aulas, sobre nossas turmas, trocando experiências".

Além dessas estratégias, notou-se que a falta de tempo citada constantemente pelos participantes pode ser entendida como uma forma de justificar um possível fracasso na convivência, deliberação coletiva e apoio da profissão: "Nós não temos muito tempo aqui na escola, porque todos precisam dar aulas em mais de uma escola, e isso nos limita muito" (Rodrigo). Pensando ainda sobre essa falta de tempo, pode-se citar aqui a dificuldade encontrada pelos professores em conseguir um horário disponível para a realização dos grupos, que durante a realização da pesquisa foram remarcados diversas vezes.

Gernet (2010) aponta que essas estratégias construídas e mantidas pelos trabalhadores funcionam como uma forma de proteção contra o sofrimento gerado pelo trabalho e têm como principal finalidade permitir que os sujeitos se mantenham trabalhando. Tais estratégias são utilizadas como uma tentativa de afastar o risco de adoecimento psíquico e físico.

Nota-se que a rotina de trabalho dos professores é extremamente desgastante, exigindo dedicação intensa ao trabalho, flexibilidade e capacidade de adaptação a um cenário instável e a demandas cada vez mais complexas. A fim de alcançar o reconhecimento, impõem-se um ritmo frenético que, embora dê visibilidade às suas contribuições, acarreta sofrimento e sobrecarga que passa despercebido pelos professores, mas que causa profundos impactos em sua saúde e subjetividade.

\section{Relações de trabalho na escola}

Pretende-se abordar aqui como se dão as relações entre os professores no ambiente de trabalho, se há ou não espaços de convivência nesse contexto e o quanto o trabalho influencia as relações dos professores fora do ambiente de trabalho.

Embora relatem que mantenham um relacionamento cordial e prazeroso em seu ambiente, constatou-se que os participantes apresentam um relacionamento muito superficial com os colegas. Essa superficialidade fica bastante evidente na seguinte fala de Rodrigo: "Existe um ambiente prazeroso na escola, nós nos falamos, conversamos, existe aquele toque, 'Oi, como é que está? Tudo bem?'.

De acordo com Bauman (2004), atualmente os indivíduos têm evitado se relacionar e estabelecer vínculos, uma vez que exigem maior dedicação e até mesmo desgaste emocional para conservá-los, tendo em vista que os vínculos sociais, hoje, estão significativamente mais frágeis e superficiais.

Notou-se uma contradição nas falas dos participantes que, ao mesmo tempo em que afirmam ter um bom relacionamento com os colegas, referem que enfrentam algumas dificuldades com relação à parte pedagógica e também com aspectos referentes à comunicação dentro da escola, conforme fala Vanessa: “... o relacionamento é bom, é a parte pedagógica que eu realmente, agora tá me deixando decepcionada". 0 depoimento de Rodrigo também apresenta essas dificuldades:

... o que acontece é que eu não fico sabendo dessas informações até porque, em vez de dar essas informações em uma quinta-feira que tem o horário 
reservado para reuniões é dado em outro dia.... Aí acontece isso: eu não fico sabendo das coisas.

No que diz respeito às relações no ambiente de trabalho, Perrenoud (2001) aponta que os professores não falam sobre suas práticas, não dividem seus conhecimentos. Além disso, não possuem uma forma de comunicação comum para falar de seus alunos, de seus erros, de suas angústias e de suas estratégias de enfrentamento do inesperado. Nesse sentido, manter laços sociais positivos no ambiente de trabalho propicia que os sujeitos possam contar com um suporte social que está diretamente relacionado a maior satisfação e reconhecimento, facilitando as resoluções de dificuldades e conflitos, além de melhorar as condições de ajustamento da saúde física e mental (Codo, 1999).

Dentro desse contexto, pode-se analisar também que os professores, de fato, não possuem um espaço de convivência no ambiente da escola. Essa situação gera incômodo nesses profissionais, que relataram sentir falta dessa conivência com os outros colegas. Essa insatisfação pode ser observada nas palavras de Vanessa: “... as reuniões de quinta-feira começaram o ano acontecendo toda hora.... depois sumiram, aí agora não tem tido reunião. Eu sinto a necessidade de encontrar colegas, discutir alguma coisa e não tem acontecido". 0 mesmo se nota nas palavras de Rodrigo: "... nós não temos tempo para nos encontrar.... nós temos muita capacidade para muitos projetos, só que a gente esbarra em não ter espaço".

Aguiar (2008) considera que a maioria das escolas não proporciona um espaço de escuta, de acolhimento, no qual os professores possam dividir suas angústias diárias, refletir e elaborar suas atitudes e comportamentos a fim de proporcionar um tempo e um lugar para que os sujeitos também possam implicar seu desejo no ambiente de trabalho. Trabalhar vai muito além de somente realizar atividades produtivas, é também conviver. Nesse sentido, uma organização de trabalho saudável deve se preocupar também em fornecer espaços de convivência nos quais as pessoas possam exercitar as regras de sociabilidade e, por consequência, o aspecto social do trabalho e os aspectos referentes à defesa e realização do ego, ou seja, o mundo subjetivo (Dejours, 2001).

No que diz respeito às resoluções dos problemas, os participantes relataram que problemas pontuais são mais facilmente resolvidos coletivamente, porém quando os problemas precisam do envolvimento de mais pessoas, as coisas não funcionam com tanta eficácia, sendo esses sempre protelados, conforme relatos abaixo:

Os problemas de grupo são mais difíceis, a gente demora muito tempo para tomar soluções, e eu vejo assim, não é fácil, até porque os professores todos não conseguem se encontrar para aquilo tomar corpo e ter alguma atitude e espaço para essa solução de problemas (Vanessa).

Quando os problemas são pontuais, realmente as soluções ficam mais práticas. É com o aluno: vamos resolver. Mas quando é com uma turma, é numa escala maior, já complica um pouco mais. Quando envolve professores de diferentes disciplinas ou precisa de um grupo maior, tudo vai ficando para depois (Rodrigo).

A equipe diretiva da escola nem sempre consegue dar suporte para que os professores desenvolvam suas tarefas de forma satisfatória. Não tendo o apoio necessário para dividir suas dúvidas e angústias, sanar seus questionamentos e formular possíveis soluções, os professores acabam recaindo em uma prática solitária, o que acarreta um sentimento de insegurança e desamparo (Aguiar, 2008). Nesse sentido, Lancman citado por Dejours (2008) considera importantíssima a existência de espaços de discussão em que os trabalhadores sejam ouvidos e debatam suas opiniões de forma democrática, sem a exigência de argumentos técnicos.

No que se relaciona ao relacionamento com os alunos, os professores apontaram que este é bastante satisfatório. Os alunos demonstram carinho e procuram manter uma proximidade com eles. No entanto, observou-se que eles não se sentem muito à vontade com toda essa proximidade, não sabendo muito bem como lidar com esse vínculo que exige grande investimento afetivo, como se constata no fragmento a seguir: "...tem um aluno que toda vez que me enxerga ele vem e diz 'Professora, me dá um beijinho, tudo bom?' E eu fico toda assim... e agora, o que eu faço? Porque a gente nem sabe lidar com isso" (Vanessa). Rodrigo também demonstra esse desconforto:

... essa nossa tagarelice nos faz chegar perto do aluno, eles podem não gostar da minha aula, mas 
às vezes estou nos corredores e eles se aproximam "professor" e eles contam muito da vida deles e a gente tem que cuidar muito porque às vezes é preciso cortar, né? (Rodrigo).

De acordo com Codo (1999), para as tarefas que exigem um investimento afetivo maior, isto é, aquelas relacionadas ao cuidado, se torna imprescindível o estabelecimento de vínculos a fim de atingir o bem-estar dos outros. Nesse sentido, o professor, para que possa desempenhar sua função satisfatoriamente, necessita estabelecer esses laços. No entanto, embora esses vínculos afetivos sejam necessários, de acordo com Aguiar (2008), esse grau de envolvimento dos professores com o seu trabalho e no contato com os alunos e suas famílias são fatores determinantes no adoecimento desses profissionais.

Ainda no que se refere às relações, pode-se constatar que a rotina do trabalho docente tem influenciado diretamente nas relações interpessoais dos professores, limitando, assim, seu tempo com a família, suas atividades de lazer e vida social como se constata na fala de Rodrigo: "... às vezes, eu tenho que priorizar. Agora eu tenho que ficar com a família, porque eu preciso desse descanso, mas chego ao final do ano, eu tenho que diminuir, aí eu faço o seguinte: se no sábado eu trabalho, no domingo eu fico com a família". Outra participante também aborda essa questão em sua fala: "... quando eu tinha os filhos em casa, algumas vezes eu me incomodava com um aluno, chegava em casa e brigava com os filhos. Os filhos foram muito mais exigidos por mim do que os alunos" (Vanessa).

Para Codo $(1999,2002)$, o trabalho docente parece tomar tempo e afeto que deveriam ser destinados à família, pois o ofício de professor exige que se leve também o trabalho para além do ambiente escolar. 0 trabalho, como se encontra estruturado hoje, vem subtraindo o espaço da vida particular dos trabalhadores, interferindo diretamente na relação com o cônjuge e com os filhos. Assim, conforme o autor, o professor vivencia um constante dilema, pois ele precisa trabalhar e, às vezes, em mais de uma escola. Mas, por outro lado, também necessita se dedicar à família, à rotina diária da casa sendo que, frequentemente, esse dilema pode resultar em sofrimento psíquico e exaustão emocional.

Percebe-se que o docente é chamado a construir vínculos essenciais para o desenvolvimento de seu trabalho, mas que são fontes de sofrimento, pois exigem doação ilimitada do professor, que leva seu compromisso com colegas e alunos para além da sala de aula, havendo um lugar cada vez mais restrito para o não trabalho e para outros relacionamentos de sua vida.

Constatou-se, ainda, que as relações de trabalho na escola são diretamente afetadas pelos desafios da profissão, sendo baseadas em esforços conjuntos para o alcance dos objetivos pedagógicos. Entretanto, não há espaço e tempo efetivos para convivência, construção de laços, compartilhamento de vivências e emancipação profissional, o que mostra a importância da intervenção psicológica na escola, dentro da perspectiva da psicodinâmica do trabalho, propiciando a escuta coletiva e a construção de novas relações.

\section{Considerações finais}

A realização desta pesquisa permitiu observar que, realmente, os professores estão enfrentando um sofrimento intenso diante da realidade atual de sua profissão e que as relações de trabalho estão enfraquecidas, o que só agrava o mal-estar experienciado pelos professores. Além disso, constatou-se que, mesmo diante de todas essas dificuldades, os professores ainda conseguem encontrar realização e prazer no exercício de sua profissão, sendo que buscam, dentro de suas limitações, encontrarem maneiras de romper com esse sofrimento vinculado à profissão, ressignificando-o e transformando-o a partir de sua contribuição ao processo educativo.

Embora a pesquisa tenha sido realizada com um recorte muito pequeno da população de professores, os dados obtidos foram bastante significativos e relevantes, pois evidenciaram a realidade docente atual e suscitaram questionamentos, instigando novos estudos que busquem, cada vez mais, ampliar o conhecimento e a reflexão sobre o tema.

Além disso, desenvolver esta investigação na perspectiva da psicodinâmica do trabalho revelou a importância da escuta coletiva e dos espaços de discussão no intuito de aprimorar as relações de trabalho pela abertura de espaços de comunicação e interlocução, rumo à emancipação profissional e à reflexão sobre seus desafios e conquistas, bem como, sobre as demandas de sua profissão. Assim, considera-se fundamental a intervenção do psicólogo nesse contexto, promovendo a escuta coletiva, 
em busca de novas formas de realização e saúde na profissão docente, o que pressupõe convivência, cooperação e ações coletivas.

\section{Referências}

Aguiar, R. M. R. (2008). Mal-estar na educação: O sofrimento de professores. Curitiba: Juruá.

Bardin, L. (2004). Análise de conteúdo. Lisboa: Edições 70.

Bauman, Z. (2001). Modernidade líquida. Rio de Janeiro: Ed. Jorge Zahar.

Bauman, Z. (2004). Amor líquido: Sobre a fragilidade dos laços humanos. Rio de Janeiro: Ed. Jorge Zahar.

Brasil. (1997). Ministério da Saúde. Conselho Nacional de Saúde, Comitê de Ética em Pesquisa em Seres Humanos. Resolução 196/96, de 10 de outubro de 1996: Diretrizes e normas regulamentadoras de pesquisas envolvendo seres humanos. Brasília.

Codo, W. (Org.). (1999). Educação: carinho e trabalho. Petrópolis, RJ: Vozes.

Codo, W., Jacques, M. G. (Org.). (2002). Saúde mental \& trabalho: Leituras. Petrópolis, RJ: Vozes.

Dejours, C. (1992). A loucura do trabalho: Estudo de psicopatologia do trabalho. (5a ed.). São Paulo: Cortez Oboré.

Dejours, C. (1994). Psicodinâmica do trabalho: Contribuições da escola dejouriana à análise da relação prazer, sofrimento e trabalho. São Paulo: Atlas.

Dejours, C. (1999). Conferências brasileiras: Identidade, reconhecimento e transgressão no trabalho. São Paulo: Fundap: EAESP/ FGV.

Dejours, C. (2001). A banalização da injustiça social. (4a ed.). Rio de Janeiro: Editora FGV.

Dejours, C. (2004). Subjetividade, trabalho e ação. Produção, 14(3). doi:10.1590/S0103-65132004000300004.

Dejours, C. (2008). A metodologia em psicopatologia do trabalho. In: S. Lancman \& L. I. Sznelwar (Org.). Christophe Dejours: Da psicopatologia à psicodinâmica do trabalho. (pp. 107-128). Rio de Janeiro: Editora Fio Cruz; Brasília: Paralelo 15.

Esteve, J. M. (1999). O mal estar - docente: A sala de aula e a saúde dos professores. Bauru, SP: EDUSC.
Ferreira, M. C. (2010) "Chegar feliz e sair feliz do trabalho": aportes do reconhecimento no trabalho para uma ergonomia aplicada à qualidade de vida no trabalho. In: A. M. Mendes (Org.). Trabalho e saúde - O sujeito entre a emancipação e servidão. (pp. 40-53). Curitiba: Juruá. PMid:21152708.

Gernet, I. (2010). Psicodinâmica do reconhecimento. In: A. M. Mendes. (Org.). Psicodinâmica e clínica do trabaIho: Temas, interfaces e casos brasileiros. (pp. 61-76). Curitiba: Juruá.

González, R., Fernando, L. (2002). Pesquisa qualitativa em psicologia: Caminhos e desafios. São Paulo: Pioneira Thomson Learning.

Lane, S. T. M., Codo, W. (Org.). (1994). Psicologia Social: O homem em movimento. São Paulo: Editora Brasiliense.

Martins, S. R. (2010). Tempo antes do adoecer: Relações entre saúde e os processos psicodinâmicos do reconhecimento do trabalho. In: A. M. Mendes (Org.). Trabalho e saúde - O sujeito entre a emancipação $e$ servidão. Curitiba: Juruá.

Mazzotti, A. J. A. (2007). Representações da identidade docente: uma contribuição para formulação de políticas. Ensaio: Avaliação e Política Pública em Educação, 15(57).

Mendes, A. M. (Org.). (2010). Trabalho e saúde - O sujeito entre emancipação e servidão. Curitiba: Juruá.

Merlo, A. R. C., \& Mendes, A. M. B. (2009). Perspectivas no uso da psicodinâmica do trabalho no Brasil: Teoria, pesquisa, ação. Caderno de Psicologia Social e do Trabalho, 12(2).

Navarro, V. L., \& Padilha, V. (2007). Dilemas do trabalho no capitalismo contemporâneo. Psicologia e Sociedade, 19. doi:10.1590/S0102-71822007000400004.

Oliveira, D. A. (2004). A reestruturação do trabalho docente: Precarização e flexibilização. Educação Social, 25(89). doi:10.1590/S0101-73302004000400003.

Perrenoud, P. (2001). Ensinar: agir na urgência, decidir na incerteza. Porto Alegre: Artmed Editora.

Perrenoud, P. (2002). A prática reflexiva no ofício de professor: Profissionalização e razão pedagógica. Porto Alegre: Artmed.

Sennett, R. (2003). A corrosão do caráter: As conseqüências pessoais do trabalho no novo capitalismo. (7a ed.). Rio de Janeiro: Record. 